\title{
Flavonoids isolated from Citrus platymamma induced G2/M cell cycle arrest and apoptosis in A549 human lung cancer cells
}

\author{
ARULKUMAR NAGAPPAN ${ }^{1 *}$, HO JEONG LEE ${ }^{2 *}$, VENU VENKATARAME GOWDA SARALAMMA ${ }^{2}$, \\ HYEON SOO PARK ${ }^{2}$, GYEONG EUN HONG ${ }^{2}$, SILVIA YUMNAM ${ }^{2}$, SUCHISMITA RAHA $^{2}$, \\ SHOBANA NANCY CHARLES ${ }^{1}$, SUNG CHUL SHIN ${ }^{3}$, EUN HEE KIM ${ }^{4}$, WON SUP LEE ${ }^{1}$ and GON SUP KIM ${ }^{2}$ \\ ${ }^{1}$ Department of Internal Medicine, Institute of Health Sciences and Gyeongnam Regional Cancer Center, \\ School of Medicine, Gyeongsang National University, Jinju, Gyeongnam 660-702; ${ }^{2}$ Brain Korea 21 Program \\ for Leading Universities and Students, Research Institute of Life Science and College of Veterinary Medicine; \\ ${ }^{3}$ Department of Chemistry, Research Institute of Life Science, Gyeongsang National University, Jinju, Gyeongnam 660-701; \\ ${ }^{4}$ Department of Nursing Science, International University of Korea, Jinju, Gyeongnam 660-759, Republic of Korea
}

Received April 14, 2015; Accepted April 29, 2016

DOI: $10.3892 / 01.2016 .4793$

\begin{abstract}
Citrus platymamma hort. ex Tanaka belongs to the Rutaceae family and is widely used in folk medicines in Korea due to its anti-proliferative, anti-cancer, anti-oxidant, anti-inflammatory and anti-diabetic activities. However, the molecular mechanism of its anti-cancer effect is not well understood. The present study was conducted to elucidate the anti-cancer effect and molecular mechanism of flavonoids from Citrus platymamma (FCP) on A549 cells. FCP displayed concentration-dependent inhibition on A549 cells proliferation. Further, flow cytometry revealed that FCP significantly increased the sub-G1 (apoptotic cell population) and G2/M phase population, and the total number of apoptotic cells, in a dose-dependent manner. Nuclear condensation and fragmentation were also observed upon staining with Hoechst 33342 in FCP-treated A549 cells. Immunoblotting demonstrated a dose-dependent downregulation of cyclin B1, cyclin-dependent kinase 1 , cell division cycle 25 c, pro-caspases $-3,-6,-8$ and -9 ,
\end{abstract}

Correspondence to: Professor Gon Sup Kim, Brain Korea 21 Program for Leading Universities and Students, Research Institute of Life Science and College of Veterinary Medicine, Gyeongsang National University, 900 Gajwa-dong, Jinju, Gyeongnam 660-701, Republic of Korea

E-mail: gonskim@gnu.ac.kr

Professor Won Sup Lee, Department of Internal Medicine, Institute of Health Sciences and Gyeongnam Regional Cancer Center, School of Medicine, Gyeongsang National University, 90 Chilam-dong, Jinju, Gyeongnam 660-702, Republic of Korea

E-mail: 1wshmo@hanmail.net; lwshmo@gnu.ac.kr

*Contributed equally

Key words: Citrus platymamma, flavonoids, lung cancer, apoptosis, cell cycle, A549 cells and poly (adenosine diphosphate-ribose) polymerase (PARP) in FCP-treated A549 cells. In addition, FCP induced caspase-3 activation and subsequent PARP cleavage, and increased the B-cell lymphoma (Bcl)-2-associated X protein/Bcl-extra large ratio in A549 cells. These findings suggest that FCP induced G2/M arrest and apoptosis of A549 cells. The present study provides evidence that FCP may be useful in the treatment of human lung cancer.

\section{Introduction}

Lung cancer is the leading cause of cancer-associated mortality worldwide $(1,2)$. The majority of lung cancers belong to the non-small cell lung cancer (NSCLC) type, which accounts for $>80 \%$ of all cases of lung cancer (3). The main characteristic of NSCLC is its high aggressive invasion ability and metastatic properties (4). Therefore, the majority of advanced NSCLC cases require to receive combination of chemotherapy, and/or radiation treatment (5). The survival rates of patients with NSCLC are poor, and $>85 \%$ of patients succumb to disease within 5 years of diagnosis (6). Due to the low therapeutic efficacy and serious side effects of current chemotherapeutic drugs (7), a paradigm shift is obviously required for the management of this disease. In this context, recent cancer research has focused on the possibility of preventing or controlling cancer using dietary agents and phytochemicals, which are less toxic than chemotherapeutic drugs (8).

Natural substances exert their anti-cancer activity by modulating cell cycle progression and inducing apoptosis-regulatory proteins $(8,9)$. Apoptosis is a type I programmed cell death that is characterized by distinct phenotypes from necrosis, including membrane blebbing, cell shrinkage, nuclear fragmentation, chromatin condensation and apoptotic body formation $(10,11)$. The apoptotic process happens in either a caspase-dependent or -independent manner (12). In addition, B-cell lymphoma (Bcl)-2 family proteins are important for apoptosis regulation, which could be either proapoptotic, such as Bcl-2-associated $\mathrm{X}$ protein 
(Bax) or Bcl-2 homologous antagonist/killer, or antiapoptotic, such as Bcl-2 and Bcl-extra large (Bcl-xL) (13).

The cell cycle is controlled by a complex series of signaling pathways by which a cell grows, replicates its DNA and divides (14). This process includes mechanisms to ensure errors are corrected while cell replication occurs, and if the correction cannot be performed, cells enter into the apoptotic process (15). However, in cancer cells, this regulatory process malfunctions and results in uncontrolled cell proliferation (16). Therefore, induction of apoptosis and modulation of cell cycle is very important in cancer treatment with anti-cancer agents.

Citrus platymamma hort. ex Tanaka (also known as Byungkyul in Korea) belongs to the Rutaceae family, and has been used in Korean traditional medicine for the treatment of inflammatory disorders and cancer (17). Flavonoids, which are abundantly present in fresh fruits and vegetables, are known to safely modulate physiological functions and enhance anti-cancer activity $(18,19)$. Citrus species, including Citrus platymamma, contain a wide range of active components such as flavonoids, which exhibit anti-proliferative, anti-cancer, anti-oxidant, anti-inflammatory and anti-diabetic activities (20). Numerous studies have been reported on Citrus flavonoids that inhibit the growth of various cancer cells and exhibit anti-inflammatory effects in vivo and in vitro (21-23). However, the cellular mechanism of the anti-cancer properties of flavonoids from Citrus platymamma (FCP) remains to be elucidated.

Based on the above evidences, the present authors hypothesized that FCP may exert anti-cancer effects, since they have been used as a traditional medicine for cancer treatment. Therefore, in the present study, FCP were isolated and characterized, and the mechanisms of their anti-cancer effects were investigated on A549 cells. These flavonoids induced G2/M cell cycle arrest and apoptosis in A549 cells. To the best of our knowledge, the present study is the first report that elucidates the molecular mechanism of FCP in inducing apoptosis and G2/M cell cycle arrest on the A549 human lung cancer cell line.

\section{Materials and methods}

Materials and reagents. A549 human lung cancer cells were obtained from the Korean Cell Line Bank (Seoul, Korea). RPMI-1640 medium, fetal bovine serum (FBS) and antibiotics (penicillin/streptomycin) were purchasedfrom Gibco(Thermo Fisher Scientific, Inc., Waltham, MA, USA). Hoechst 33342 and 3-(4,5-dimethylthiazol-2-yl)-2,5-diphenyltetrazolium bromide (MTT) were obtained from Sigma-Aldrich (St. Louis, MO, USA). Materials and chemicals used for electrophoresis were obtained from Bio-Rad Laboratories, Inc. (Hercules, CA, USA). Antibodies against Bcl-xL (\#2762), Bax (\#2772), caspase-3 (\#9662), caspase-6 (\#9762), caspase-8 (\#9746) and caspase-9 (\#9502), cleaved caspase-3 (\#9661), poly (adenosine diphosphate-ribose) polymerase (PARP; \#9542) and cleaved PARP (\#9541), were purchased from Cell Signaling Technology, Inc. (Danvers, MA, USA). Anti-cyclin B1 (\#05-373), anti-cyclin-dependent kinase 1 (CDK1; \#06-923), anti-cell division cycle 25c (cdc25c; \#05-507) and anti- $\beta$-actin antibodies (\#MABT825) were obtained from EMD Millipore (Billerica, MA, USA).
Horseradish peroxidase (HRP)-coupled goat anti-mouse IgG ALX-211-205TS-C100 and anti-rabbit IgG ADI-SAB-301-J were purchased from Enzo Life Sciences, Inc. (Farmingdale, NY, USA). Muse ${ }^{\mathrm{TM}}$ Annexin V \& Dead Cell kit was purchased from EMD Millipore.

Isolation of flavonoids from Korean Citrus platymamma hort. ex Tanaka. The fruit of Korean Citrus platymamma hort. ex Tanaka (called Byungkyul in Korea) was obtained from the Animal Bio Resources Bank (Jinju, Korea). The flavonoids were isolated at the Department of Chemistry, Gyeongsang National University (Jinju, Korea) by Professor Sung Chul Shin. The sample was prepared according to a previously described method (24). Samples were stored at $-20^{\circ} \mathrm{C}$ until used for further experiments.

Cell culture and treatment. A549 cells were grown in RPMI-1640 medium supplemented with $10 \%$ heat-inactivated $\mathrm{FBS}$ and $1 \%$ penicillin/streptomycin in a humidified incubator with $5 \% \mathrm{CO}_{2}$ in air at $37^{\circ} \mathrm{C}$. The stock solution of flavonoids was prepared in dimethyl sulfoxide (DMSO), and subsequent dilutions were prepared for treatment. Cells grown to $70-80 \%$ confluence were untreated (control) or treated with FCP at various concentrations (100, 200, 300, 400 and $500 \mu \mathrm{g} / \mathrm{ml}$ ) for $24 \mathrm{~h}$ in complete growth medium.

Cell viability assay and morphological studies. A549 cells were seeded at $10 \times 10^{4}$ cells $/ \mathrm{ml}$ in a 12 -well plate and incubated for $24 \mathrm{~h}$. The cytotoxicity was measured by a standard MTT assay following treatment with FCP at the specified concentrations for $24 \mathrm{~h}$ at $37^{\circ} \mathrm{C}$. After 24-h incubation, $100 \mu \mathrm{l} \mathrm{MTT}$ reagent $(5 \mathrm{mg} / \mathrm{ml})$ was added to each well, and incubated at $37^{\circ} \mathrm{C}$ for $3 \mathrm{~h}$ to form formazan crystals. Then, the supernatant was discarded, and $500 \mu 1 \mathrm{DMSO}$ was added to each well to dissolve the crystals. The optical density of the cells at $540 \mathrm{~nm}$ was measured using an enzyme-linked immunosorbent assay plate reader. The morphology of flavonoids-treated A549 cells was observed under a phase contrast microscope (Olympus Corporation, Tokyo, Japan).

Flow cytometry analysis. Cells were seeded at a density of $5 \times 10^{5}$ cells/well into a 6 -well plate and treated with FCP at various concentrations $(0,91,182$ and $364 \mu \mathrm{g} / \mathrm{ml})$ for $24 \mathrm{~h}$ at $37^{\circ} \mathrm{C}$. The floating and adherent cells were collected, washed twice with cold phosphate-buffered saline (PBS) and centrifuged at $300 \times \mathrm{g}$ for $5 \mathrm{~min}$ at room temperature. The cell pellet was fixed using cold $70 \%$ ethanol (v/v) for $3 \mathrm{~h}$ at $-20^{\circ} \mathrm{C}$. The cells were washed once with PBS, and $200 \mu 1$ of the cell suspension was transferred to a fresh tube. Next, $200 \mu 1$ Muse $^{\mathrm{TM}}$ Cell Cycle kit reagent (EMD Millipore) was added to each tube and incubated for $30 \mathrm{~min}$ at room temperature in the dark. For the apoptosis assay, the floating and trypsinized cells were collected, washed once with cold PBS and centrifuged at $300 \mathrm{x}$ g for $5 \mathrm{~min}$ at room temperature. The pellet was resuspended in $1 \mathrm{ml}$ medium, and $100 \mu \mathrm{l}$ of this suspension was transferred to a new tube. Then, $100 \mu 1$ Muse $^{\mathrm{TM}}$ Annexin V \& Dead Cell kit reagent was added to each tube and incubated for $20 \mathrm{~min}$ at room temperature in the dark. Then stained samples were analyzed with a Mini Flow Cytometry Muse ${ }^{\mathrm{TM}}$ Cell Analyzer (EMD Millipore). 
TIC: from sample 2 (beung 1-1) of yeal 130215ET1.wiff(Turbo Spray)

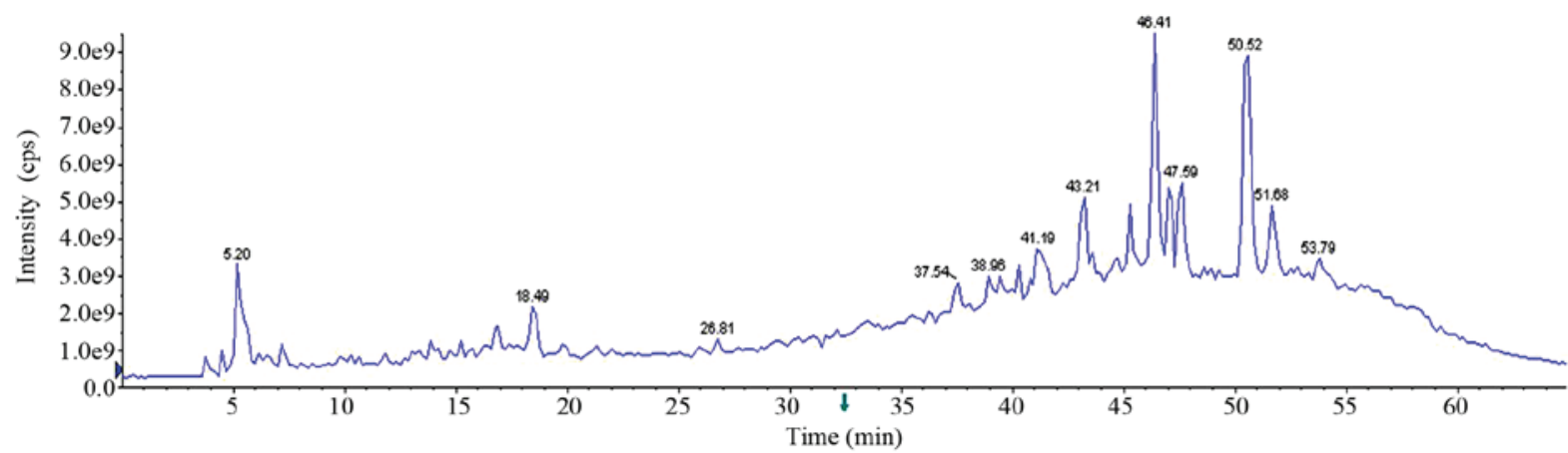

XWC of DAD signal data: $280.0 \mathrm{~nm}$ from sample 2 (beung 1-1) of yeal 130215SET1.wiff

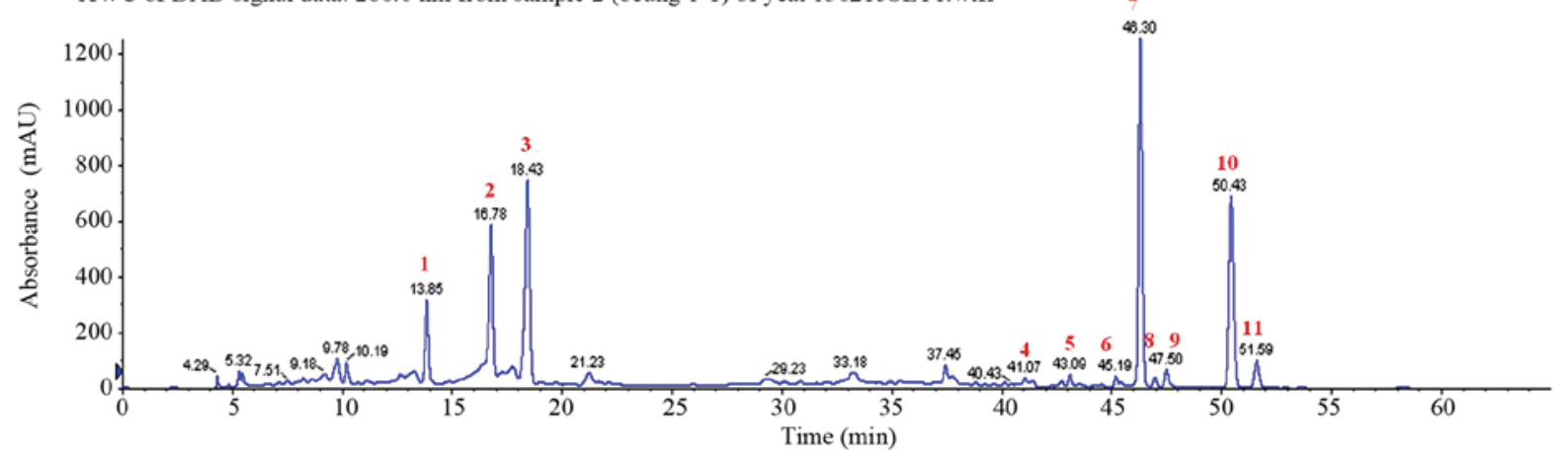

Figure 1. High-performance liquid chromatography chromatogram patterns of the fruit of Korean Citrus platymamma hort. ex Tanaka recorded at $280 \mathrm{~nm}$. The identified flavonoids from the peaks marked in red were as follows: 1, neoeriocitrin; 2, naringin; 3, hesperidin; 4, isosinensetin; 5, sinensetin; 6, tetramethyl-O-isoscutellarein; 7, nobiletin; 8, tetramethoxyflavone; 9, heptamethoxyflavone; 10, tangeretin; and 11, hydroxypentamethoxyflavone. TIC, total ion chromatogram; XWC, extracted wavelength chromatogram; DAD, diode array detector; cps, counts per second; mAU, milli-absorption units.

4',6-diamidino-2-phenylindole (DAPI) fluorescent staining. A549 cells were grown to $80 \%$ confluence on 10 -mm diameter glass slides placed in 24-well plates and treated with FCP at the indicated concentrations for $24 \mathrm{~h}$ at $37^{\circ} \mathrm{C}$. Cells were washed with cold PBS and fixed with $37 \%$ formaldehyde (1:4 dilution with $95 \%$ ethanol) for $10 \mathrm{~min}$ at room temperature. The fixed cells were washed with PBS and stained with DAPI and VECTASHIELD ${ }^{\circledR}$ (catalog number H-1500; Vector Laboratories, Inc., Burlingame, CA, USA). Cells were mounted in Fluorescence Mounting Medium (Dako, Glostrup, Denmark), and the nuclear morphology of the cells was examined by fluorescence microscopy (magnification, x400; Leica Microsystems GmbH, Wetzlar, Germany).

Western blot analysis. The protein content was quantified using a Bradford assay (Bio-Rad Laboratories, Inc.). Proteins were separated by $12 \%$ sodium dodecyl sulfate-polyacrylamide gel electrophoresis and transferred to a polyvinylidene fluoride membrane (Immunobilon-P, $0.45 \mathrm{~mm}$; EMD Millipore) using the TE 77 semi-dry transfer unit (GE Healthcare Life Sciences, Chalfont, UK). The membranes were blocked with $5 \%$ non-fat milk in Tris-buffered saline containing 0.1\% Tween 20 (pH 7.4) at room temperature for $1 \mathrm{~h}$. Membranes were incubated overnight at $4^{\circ} \mathrm{C}$ with the primary antibodies (dilution, 1:1,000), and a second incubation was conducted with HRP-conjugated secondary antibodies (dilution, 1:1,000) for $3 \mathrm{~h}$ at room temperature. The bound antibodies were visualized using an enhanced chemiluminescence kit (GE Healthcare Life Sciences), and images were acquired using a ChemiDoc ${ }^{\mathrm{TM}} \mathrm{XRS}+$ system with Image $\mathrm{Lab}^{\mathrm{TM}}$ software version 4.1 (Bio-Rad Laboratories, Inc.).
Statistical analysis. Data are expressed as the mean \pm standard deviation of $\geq 3$ independent experiments. Statistical analysis was performed with Student's $t$-test and one-way analysis of variance (ANOVA), using SPSS version 10.0 (SPSS, Inc., Chicago, IL, USA). $\mathrm{P}<0.05$ was considered to indicate as statistical significant difference. Significant differences were determined using ANOVA with post-test Neuman-Keuls method for comparisons of $\geq 3$ treatment groups, while Student's $t$ test was used for comparisons of two groups.

\section{Results}

High-performance liquid chromatography (HPLC) chromatogram. The HPLC chromatogram of the fruit of Korean Citrus platymamma hort. ex Tanaka, which was recorded at $280 \mathrm{~nm}$, is shown in Fig. 1, where peaks corresponding to 11 different flavonoids were clearly distinguished. These peaks were identified based on their HPLC retention times, molecular ion masses and spectroscopic data. In total, 11 flavonoids were successfully identified from Korean Citrus platymamma hort. ex Tanaka, including neoeriocitrin, naringin, hesperidin, isosinensetin, sinensetin, tetramethyl-O-isoscutellarein, nobiletin, tetramethoxyflavone, heptamethoxyflavone, tangeretin and hydroxypentamethoxyflavone. The quantification is shown in Table I.

Effect of FCP on A549 cells proliferation. The anti-proliferative effect of FCP was investigated by MTT assay in A549 cells incubated for $24 \mathrm{~h}$ with different doses of $\operatorname{FCP}(0,100,200,300$, 400 and $500 \mu \mathrm{g} / \mathrm{ml})$. As indicated in Fig. 2A, FCP significantly 
Table I. Spectral data and retention time of the identified flavonoids isolated from Korean Citrus platymamma hort. ex Tanaka.

\begin{tabular}{|c|c|c|c|c|}
\hline No. & Compound & Retention time (min) & {$[\mathrm{M}+\mathrm{H}]^{+} /[\mathrm{M}-\mathrm{H}]^{-}(\mathrm{m} / \mathrm{z})$} & MS/MS (m/z) \\
\hline 1 & Neoeriocitrin & 13.85 & $-/ 595$ & $459,329,311,287,151,135,107$ \\
\hline 2 & Naringin & 16.78 & $-/ 579$ & $459,313,271,193,151$ \\
\hline 3 & Hesperidin & 18.43 & $-/ 609$ & $608,325,301$ \\
\hline 4 & Isosinensetin & 41.07 & 373 & $358,357,343,329,181,165$ \\
\hline 5 & Sinensetin & 43.09 & 373 & $358,357,343,340,329,312,162$ \\
\hline 6 & Tetramethyl-O-isoscutellarein & 45.19 & 343 & $328,313,299,285,240,152,133$ \\
\hline 7 & Nobiletin & 46.30 & 403 & $388,373,355,327,241,211,165$ \\
\hline 8 & Tetramethoxyflavone & 46.95 & 343 & $327,313,282,150$ \\
\hline 9 & Heptamethoxyflavone & 47.50 & 433 & $418,403,385,211,165$ \\
\hline 10 & Tangeretin & 50.43 & 373 & $358,343,325,297$ \\
\hline 11 & Hydroxypentamethoxyflavone & 51.59 & 389 & $374,359,341,165$ \\
\hline
\end{tabular}

M, molecular mass; MS, mass spectrometry; -/, negative ions.

A

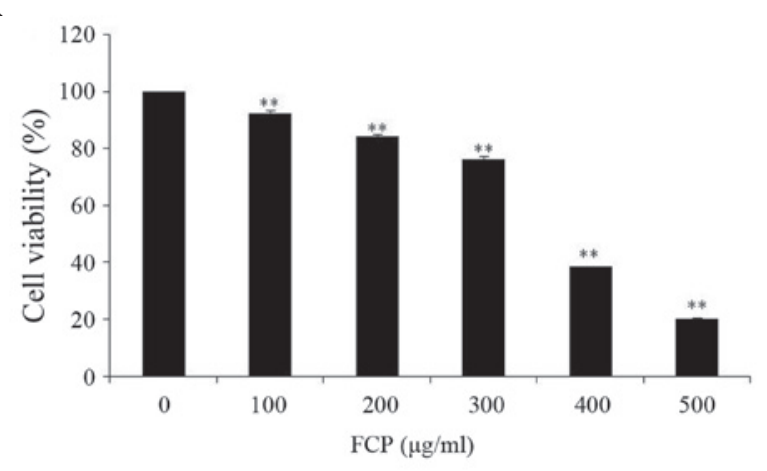

B

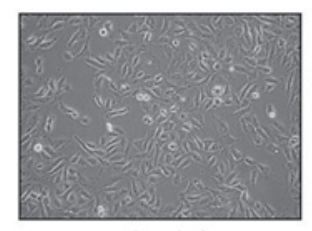

$0 \mu \mathrm{g} / \mathrm{ml}$

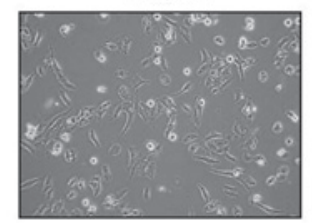

$182 \mu \mathrm{g} / \mathrm{ml}$

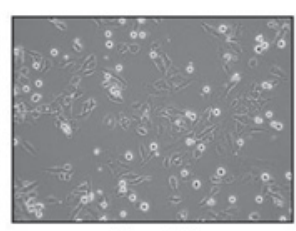

$91 \mu \mathrm{g} / \mathrm{ml}$

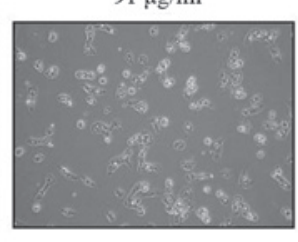

$364 \mu \mathrm{g} / \mathrm{ml}$

Figure 2. Inhibitory effect of FCP on A549 cell growth. (A) A549 cells were treated with the indicated concentrations of FCP for 24 h, and cell viability was assessed by 3-(4,5-dimethylthiazol-2-yl)-2,5-diphenyltetrazolium bromide assay. Cell viability is expressed as the percentage of relative absorbance of the FCP-treated groups compared with the control. (B) Morphology of A549 cells treated with or without FCP for 24 h and examined under light microscopy (magnification, x400). Data were obtained from three independent experiments $\left({ }^{* *} \mathrm{P}<0.01\right.$ vs. control).FCP, flavonoids from Citrus platymamma.

inhibited the viability of A549 cells in a dose-dependent manner. The results revealed that the half maximal inhibitory concentration $\left(\mathrm{IC}_{50}\right)$ of FCP was $364 \mu \mathrm{g} / \mathrm{ml}$. According to their $\mathrm{IC}_{50}$ value, the concentrations of flavonoids used in the following experiments were $0,91,182$ and $364 \mu \mathrm{g} / \mathrm{ml}$. In addition, microscopic examination revealed that morphological changes in cell shape such as cell shrinkage, and a gradual decrease in the living cell population, were observed with increasing concentrations of FCP (Fig. 2B). These results suggest that FCP have anti-proliferative effects on A549 cells.

FCP induced G2/M arrest by downregulation of cyclin B1, $C D K 1$ and $c d c 25 c$ proteins. To investigate the mechanisms responsible for the anti-proliferative effects of FCP, the cell cycle progression of A549 cells following FCP treatment at the specified concentrations was examined by flow cytometry. The sub-G1 apoptotic cell population and G2/M phase population were significantly increased in a dose-dependent manner, whereas the number of cells in the G0/G1 and S phases were remarkably decreased (Fig. 3A). Fig. 3B shows the quantitative representations of cell cycle progression in A549 cells treated with FCP, which were observed to be dose-dependent. These results indicate that FCP are able to induce $\mathrm{G} 2 / \mathrm{M}$ arrest and apoptosis in A549 cells.

Cyclin B1, cdc2 and cdc25c are important in the cell cycle during the G2/M phase (14). This phase is controlled by formation of a complex of cyclin B1 and CDK1, which is regulated by cdc25c (25). In the present study, the effect of FCP on the regulatory proteins involved in $\mathrm{G} 2 / \mathrm{M}$ arrest was examined by immunoblotting, which revealed that FCP significantly decreased the expression levels of cyclin B1, CDK1 and cdc25c proteins in a dose-dependent manner (Fig. 3C). These data suggest that FCP induce G2/M arrest by downregulation of cyclin B1, CDK1 and cdc25c proteins in A549 cells.

FCP inducedapoptosis in A549 cells. Induction of apoptosis was examined in A549 cells following FCP treatment by Annexin V -fluorescein isothiocyanate (FITC)/propidium iodide (PI) double-labelled flow cytometry and Hoechst 33342 staining. In FCP-treated A549 cells, the total apoptotic cell proportion was significantly increased in a dose-dependent manner (Fig. 4A and B), and the late apoptotic cell proportion was higher 
A

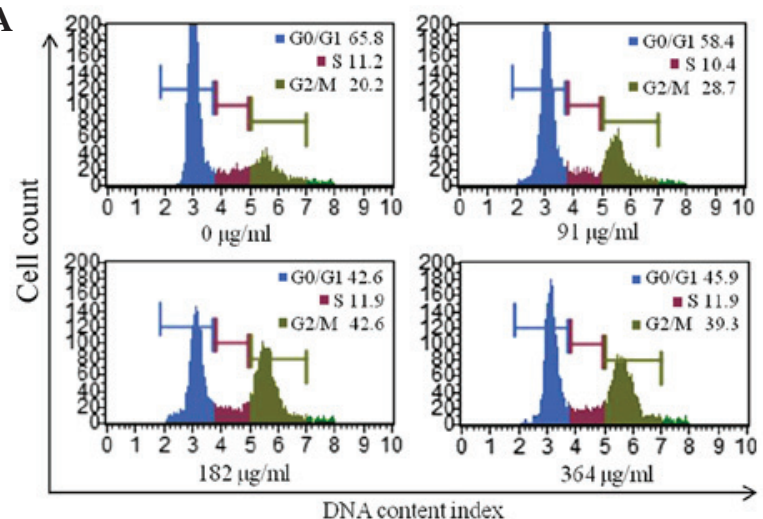

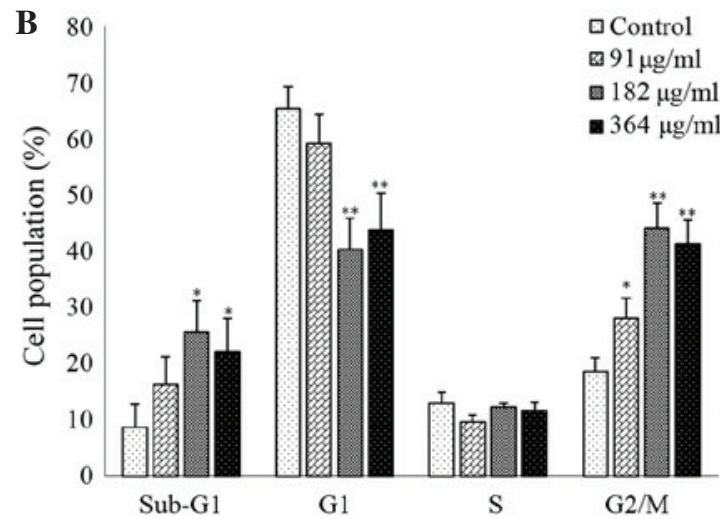

C
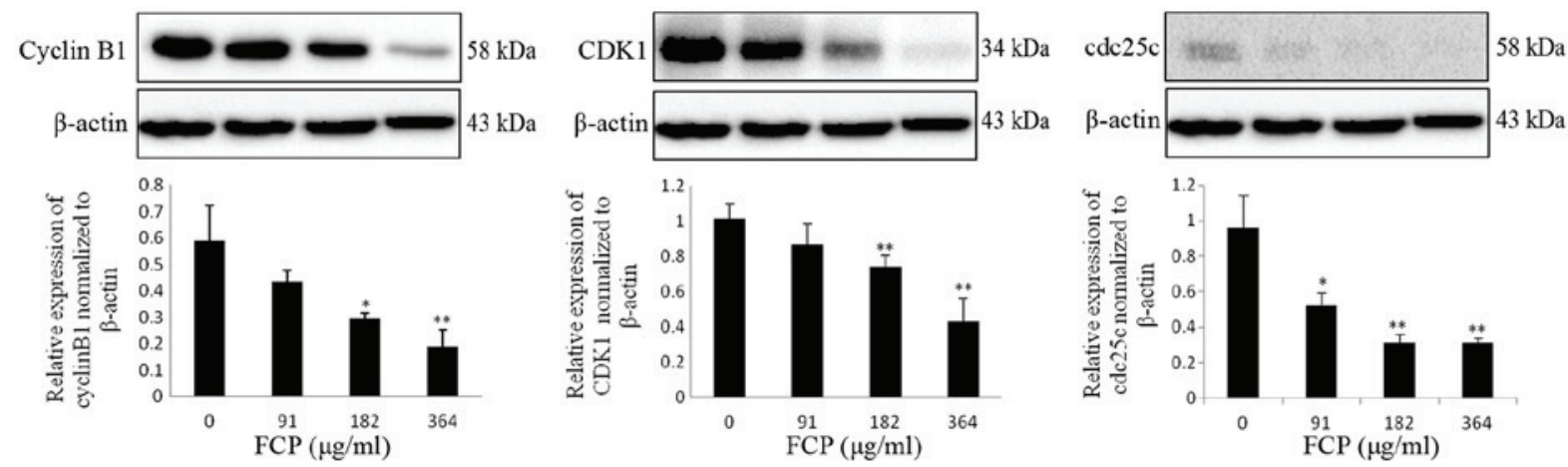

Figure 3. FCP induced G2/M cell cycle arrest by modulation of cell cycle proteins. (A) A549 cells were treated with various concentrations of FCP for 24 h. Cell cycle proportions were determined using Muse ${ }^{\mathrm{TM}}$ Cell Cycle kit, and the stained samples were analyzed by flow cytometry. (B) Quantitative data indicate significant accumulation of FCP-treated A549 cells at sub-G1 and G2/M phases. (C) Equal amounts of cell lysates (30 $\mu \mathrm{g}$ ) were subjected to sodium dodecyl sulfate-polyacrylamide gel electrophoresis and analyzed by immunoblotting. Densitometric analyses of cyclin B1, cyclin-dependent kinase 1 and cell division cycle $25 \mathrm{c}$ proteins were expressed as the mean \pm standard deviation of three independent experiments $\left({ }^{*} \mathrm{P}<0.05\right.$, ${ }^{* *} \mathrm{P}<0.01$ vs. control). All experiments were performed in triplicate. CDK1, cyclin-dependent kinase 1; cdc25, cell division cycle 25c; FCP, flavonoids from Citrus platymamma .

A

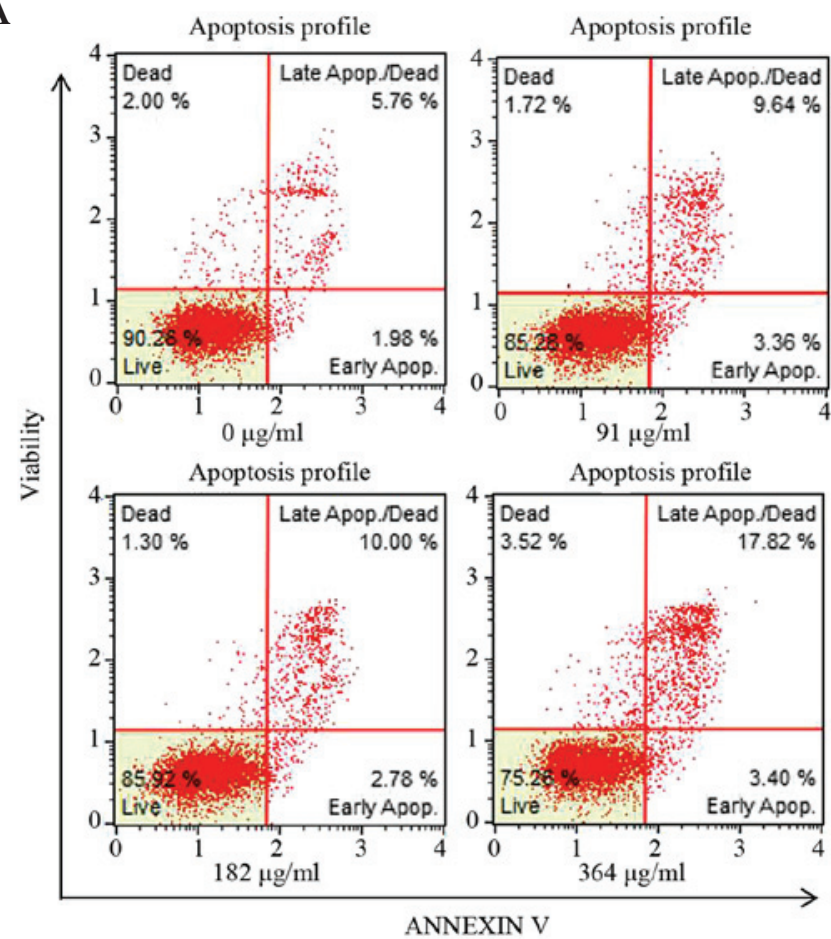

B

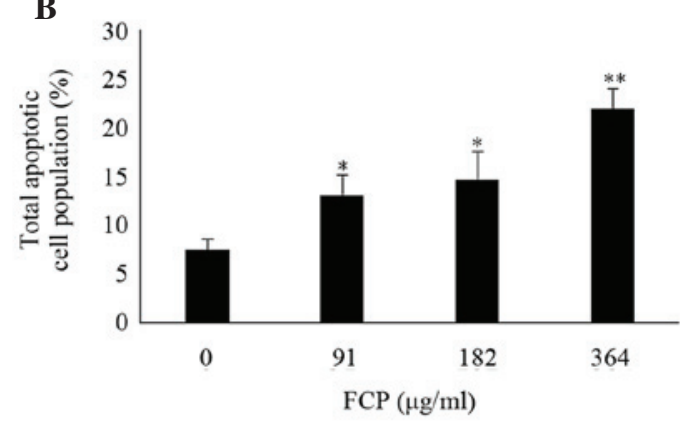

C

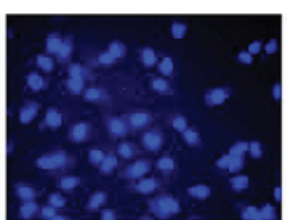

$0 \mu \mathrm{g} / \mathrm{ml}$

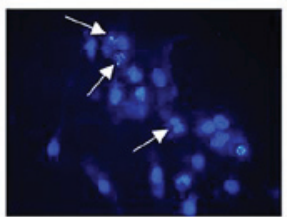

$182 \mu \mathrm{g} / \mathrm{ml}$

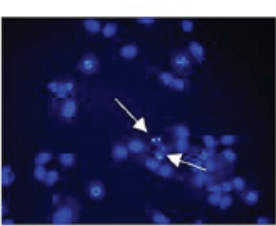

$91 \mu \mathrm{g} / \mathrm{ml}$

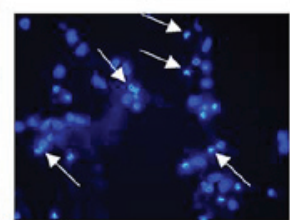

$364 \mu \mathrm{g} / \mathrm{ml}$

Figure 4. FCP induced apoptosis of A549 cells. (A) A549 cells were treated with FCP at the indicated concentrations for 24 h, and apoptosis was assessed by Annexin V-propidium iodide double staining using Mini Flow Cytometry Muse ${ }^{\mathrm{TM}}$ Cell Analyzer. (B) Quantitative data indicate that total apoptosis significantly increased in 182 and $364 \mu \mathrm{g} / \mathrm{ml} \mathrm{FCP-treated} \mathrm{cells} \mathrm{Data} \mathrm{were} \mathrm{expressed} \mathrm{as} \mathrm{the} \mathrm{mean} \pm$ standard deviation of three independent experiments ("P $<0.05$, ${ }^{* *} \mathrm{P}<0.01$ vs. control). (C) Hoechst 33258 staining of A549 cells treated with or without FCP for $24 \mathrm{~h}$ (white arrows indicate fragmented or condensed nuclei; magnification, x200). Apop, apoptosis; FCP, flavonoids from Citrus platymamma. 
A
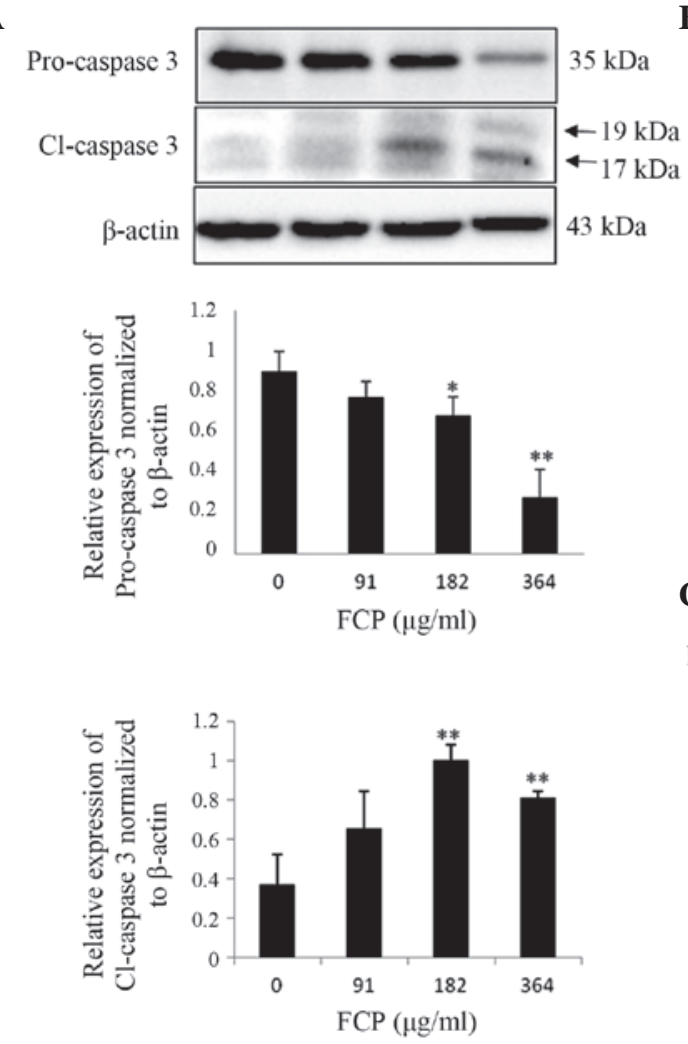

D

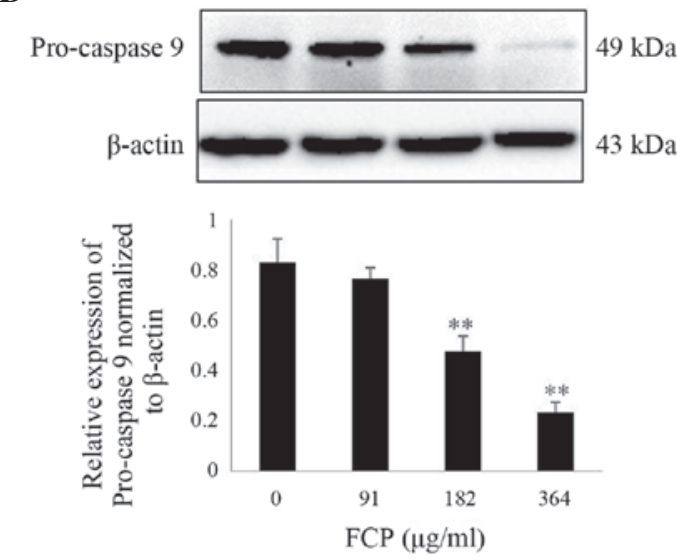

$\mathbf{F}$
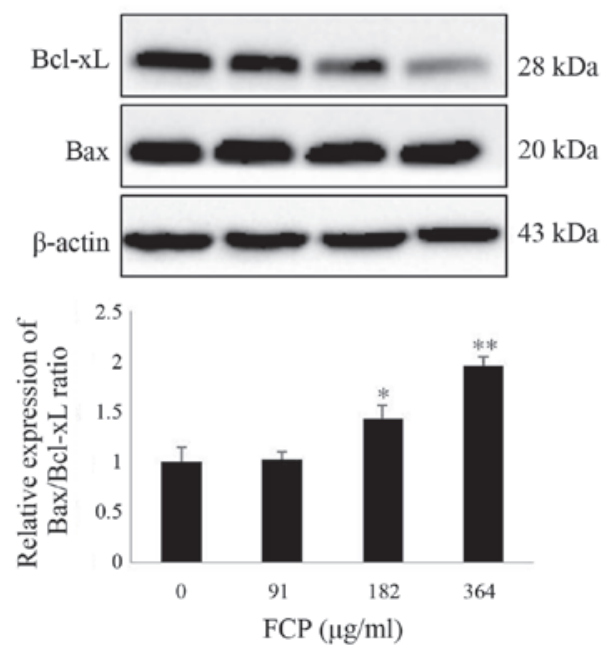

B
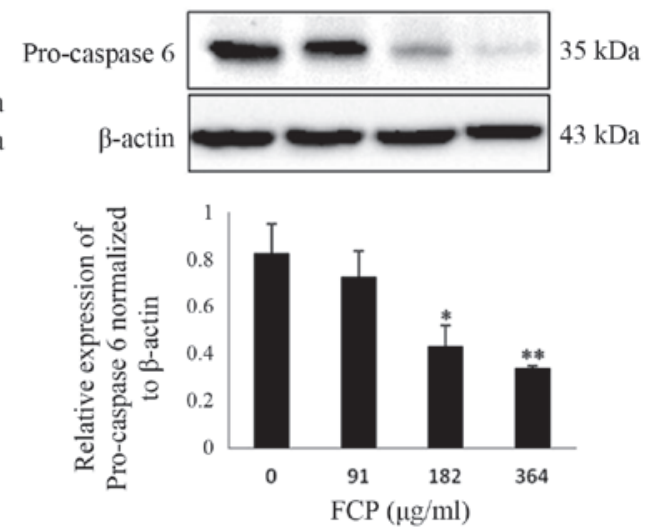

C
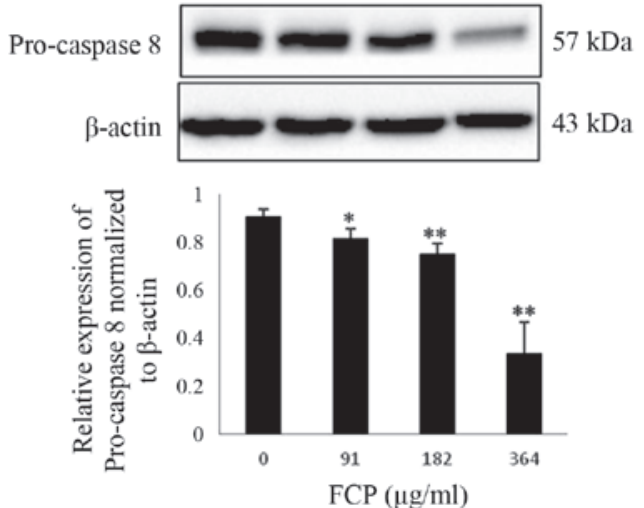

$\mathbf{E}$
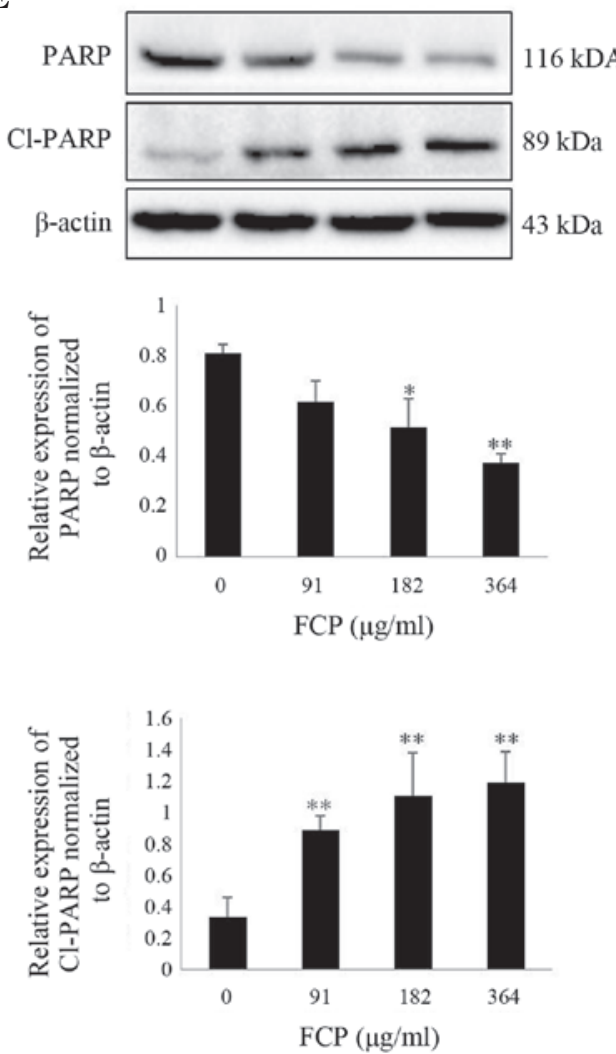

Figure 5. FCP induce caspase-3 activation and subsequent cleavage of PARP in A549 cells. Cells were treated with FCP at the indicated concentrations for $24 \mathrm{~h}$, and $30 \mu \mathrm{g}$ of the cell lysates were subjected to sodium dodecyl sulfate-polyacrylamide gel electrophoresis and analyzed by immunoblotting. Densitometric analyses of (A) pro-caspase-3 and Cl-caspase-3 (17 kDa), pro-caspases (B) -6, (C) -8 and (D) -9, (E) PARP and Cl-PARP and (F) the Bcl-2-associated X protein/Bcl-extra large ratio were expressed as the mean \pm standard deviation of three independent experiments $\left({ }^{*} \mathrm{P}<0.05,{ }^{* *} \mathrm{P}<0.01\right.$ vs. control). $\mathrm{Cl}$, cleaved; $\mathrm{Bcl}$, B-cell lymphoma; FCP, flavonoids from Citrus platymamma; PARP, poly (adenosine diphosphate-ribose) polymerase. 


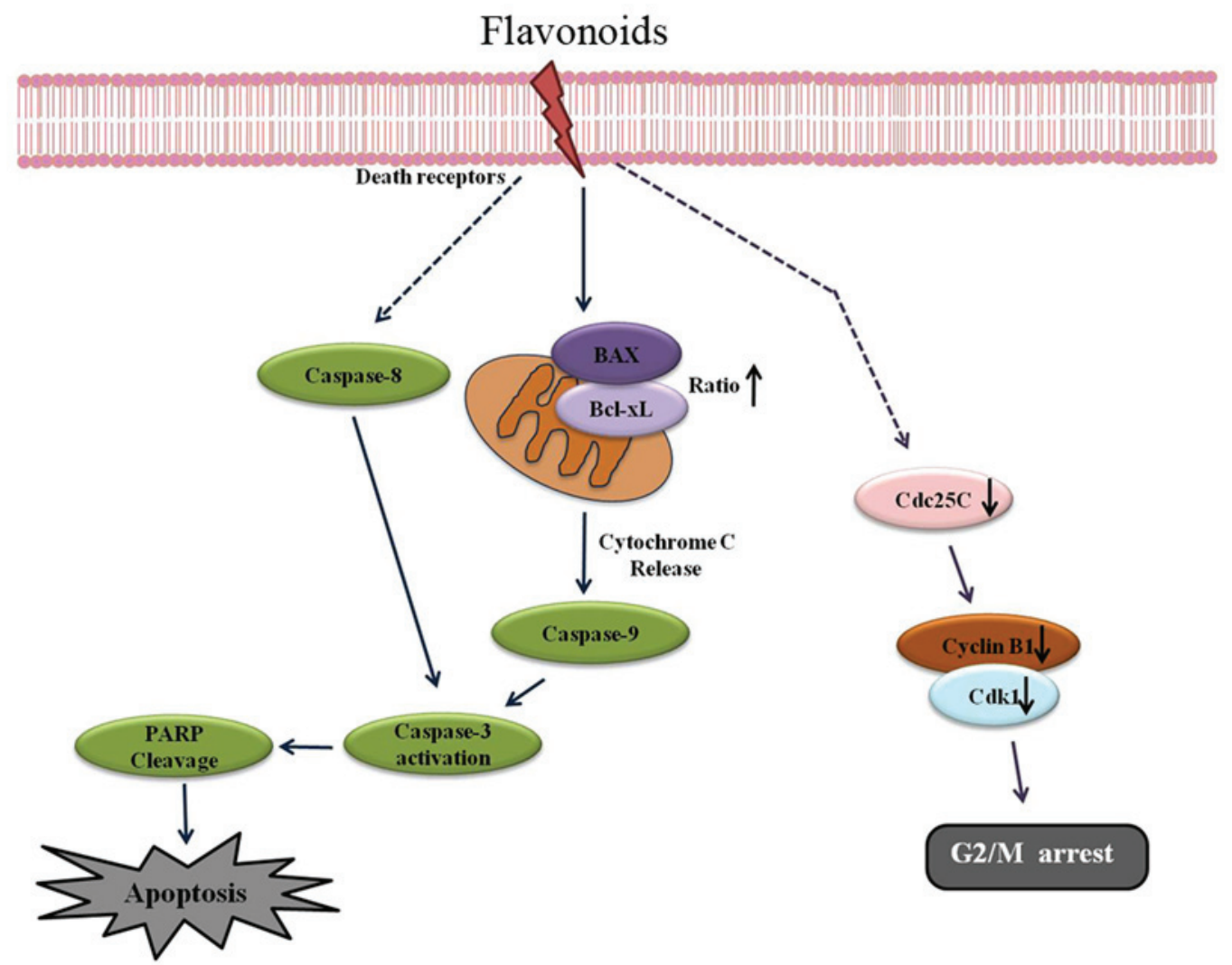

Figure 6. Schematic representation of the apoptotic effects of FCP on A549 cells. FCP induced G2/M arrest via downregulation of cdc2, cdc25c and cyclin B1, and induced caspase-dependent apoptosis partly by upregulation of the Bcl-2-associated X protein/Bcl-extra large ratio. $\left(\rightarrow\right.$ indicates activation, ${ }^{\perp}$ indicates inhibition, - indicates indirect or multiple pathways, ${ }^{\uparrow}$ indicates upregulation of proteins and ${ }^{\downarrow}$ indicates downregulation of proteins). Bcl, B-cell lymphoma; FCP, flavonoids from Citrus platymamma; PARP, poly (adenosine diphosphate-ribose) polymerase; CDK1, cyclin-dependent kinase 1; cdc, cell division cycle.

than the early apoptotic cell proportion, compared with the control. Furthermore, Hoechst 33342 staining of FCP-treated A549 cells revealed apoptotic changes in these cells, including condensed and fragmented nuclei (Fig. 4C). These data indicate that FCP are able to induce apoptosis in A549 cells.

FCP induce caspase-3 activation and subsequent cleavage of PARP in A549 cells. It is well known that caspases play a key role in modulating apoptosis (26). Among them, caspase-3 is the major effector protein of apoptosis, and is activated by an initiator caspase such as caspase-9 (27). The activation of caspases and subsequent cleavage of PARP from the native $116-\mathrm{kDa}$ form to the $89-\mathrm{kDa}$ protein is one of the hallmarks of apoptosis (28). To clarify the mechanism of FCP-induced apoptosis, the expression of apoptosis-related proteins in A549 cells following FCP treatment was examined. Upon treatment with FCP, the expression levels of PARP and pro-caspases -3 , $-6,-8$ and -9 were significantly decreased in a dose-dependent manner, which indicates caspase activation (Fig. 5A-D). FCP significantly increased the levels of cleaved PARP, a substrate of caspase-3, in A549 cells (Fig. 5E). The ratio of proapoptotic and antiapoptotic proteins is the determinant factor of apoptosis. In the present study, the $\mathrm{Bax} / \mathrm{Bcl}-\mathrm{xL}$ ratio was significantly increased by FCP in a dose-dependent manner (Fig. 5F). These results suggest that FCP induce apoptosis in A549 cells by the activation of caspases and subsequent PARP cleavage, at least in part through an increase in the ratio of Bax/Bcl-xL.

\section{Discussion}

To investigate the anti-cancer effects of FCP and their anti-cancer mechanisms in A549 human lung cancer cells, a mixture of 11 flavonoids was isolated from Korean Citrus platymamma hort. ex Tanaka and characterized by HPLC-tandem mass spectrometry. The flavonoids identified in the present study are similar to the previously reported flavonoids in other Citrus spp. $(21,29)$. The present authors previously demonstrated that the flavonoids isolated from Citrus aurantium exhibited anti-cancer and anti-inflammatory effects against various cancer cell lines $(24,30,31)$. In addition, monomers such as naringin, nobiletin and hesperidin have demonstrated anti-cancer activity in vitro and in vivo $(22,32)$. However, no reports are available regarding the anti-cancer activities of FCP. Therefore, the present study attempted to elucidate the mechanism responsible for the anti-cancer effects of FCP on A549 cells.

Firstly, the viability of A549 cells following treatment with FCP was assessed. FCP strongly inhibited A549 cell growth, and dose-dependent accumulations of sub-G1 population (apoptotic cell population) and G2/M phase populations were observed. Immunoblotting indicated that FCP induced G2/M arrest by regulation of cyclin $\mathrm{B} 1, \mathrm{CDK} 1$ and $\mathrm{cdc} 25 \mathrm{c}$ proteins in A549 cells. Previous studies demonstrated that the accumulation of $\mathrm{G} 2 / \mathrm{M}$ phase population is prominently associated with apoptosis (33). Similar to the present results, recent 
studies have reported that flavonoids induce G2/M arrest and apoptosis in a wide range of human cancer cell lines (34-36). Furthermore, FCP-induced apoptosis was confirmed by FITC-Annexin V and PI double staining in the present study, which also observed nuclear condensation, fragmentation and apoptotic bodies in FCP-treated A549 cells. These observations are consistent with biochemical and morphological changes observed during the apoptosis process (37), and thus suggest that FCP effectively induce apoptosis in A549 cells.

Caspases are a family of cysteine proteases that generally constitute key components of the apoptotic pathways (an extrinsic death receptor-mediated and an intrinsic mitochondria-mediated apoptotic pathway) (38). The intrinsic apoptotic pathway is triggered by activation of the initiator caspase-9, which directly initiates downstream events by activating caspase-3, a crucial executioner that is associated with the subsequent cleavage of its target substrate protein PARP (39-41). The present results indicated that FCP significantly decreased the levels of pro-caspases $-3,-6,-8$ and -9 , and increased the expression of cleaved caspase- 3 and cleaved PARP. In the mitochondrial apoptotic pathway, the ratio of expression of the proapoptotic and antiapoptotic proteins determines the death or survival of a cell (42). The present study demonstrated that the expression of the antiapoptotic Bcl-xL was decreased, whereas the expression of the proapoptotic Bax protein was unchanged, and the ratio of Bax/Bcl-xL was dose-dependently increased in FCP-treated A549 cells. As a result, cytochrome $c$ is released from the mitochondria into the cytosol and is able to bind apoptotic protease activating factor 1 , thus leading to the activation of caspase- 3 and subsequent cell death $(43,44)$. In addition, caspase- 8 activation was not prominent in the present study. In the intrinsic pathway-related apoptosis, caspase- 8 can be activated by a feedback mechanism (45). Therefore, the present findings suggest that FCP induce apoptosis in A549 cells at least in part through intrinsic apoptotic pathways by activation of caspase- 3 and PARP cleavage.

In summary, the present results indicate that FCP induce cell cycle arrest at the $\mathrm{G} 2 / \mathrm{M}$ phase by regulating the protein expression levels of cyclin B1, CDK1 and cdc25c, and induce caspase-dependent cell death by upregulation of the Bax/Bcl-xL ratio. Altogether, the present study provides the first report on the molecular mechanism of FCP-induced apoptosis in A549 cells, and thus reveals that Citrus platymamma may have a therapeutic potential for the treatment of human lung cancer.

\section{Acknowledgements}

The present study was supported by a grant from the National Research Foundation of Korea, which is funded by the Ministry of Science, Information and Communications Technology \& Future Planning of Korea (Seoul, Korea; grant numbers 2012M3A9B8019303 and 2012R1A2A2A06045015) and the National Research \& Development Program for Cancer Control of the Ministry for Health, Welfare and Family Affairs of Korea (Seoul, Korea; grant number 0820050).

\section{References}

1. Siegel R, Naishadham D and Jemal A: Cancer statistics, 2013. CA Cancer J Clin 63: 11-30, 2013.
2. Jung KW, Won YJ, Kong HJ, Oh CM, Seo HG and Lee JS: Prediction of cancer incidence and mortality in Korea, 2013. Cancer Res Treat 45: 15-21, 2013.

3. Meoni G, Cecere FL, Lucherini E and Di Costanzo F: Medical treatment of advanced non-small cell lung cancer in elderly patients: A review of the role of chemotherapy and targeted agents. J Geriatr Oncol 4: 282-290, 2013.

4. Park KI, Park HS, Kang SR, Nagappan A, Lee DH, Kim JA, Han DY and Kim GS: Korean Scutellaria baicalensis water extract inhibits cell cycle G1/S transition by suppressing cyclin D1 expression and matrix-metalloproteinase-2 activity in human lung cancer cells. J Ethnopharmacol 133: 634-641, 2011.

5. Molina JR, Yang P, Cassivi SD, Schild SE and Adjei AA: Non-small cell lung cancer: epidemiology, risk factors, treatment, and survivorship. Mayo Clin Proc 83: 584-594, 2008.

6. Jemal A, Siegel R, Xu J and Ward E: Cancer statistics, 2010. CA Cancer J Clin 60: 277-300, 2010.

7. Liang XJ, Chen C, Zhao Y and Wang PC: Circumventing tumor resistance to chemotherapy by nanotechnology. Methods Mol Biol 596: 467-488, 2010.

8. Hyun HB, Lee WS, Go SI, Nagappan A, Park C, Han MH, Hong SH, Kim G, Kim GY, Cheong J, et al: The flavonoid morin from Moraceae induces apoptosis by modulation of Bcl-2 family members and Fas receptor in HCT 116 cells. Int J Oncol 46: 2670-2678, 2015.

9. Jeong JW, Lee WS, Go SI, Nagappan A, Baek JY, Lee JD, Lee SJ, Park C, Kim GY, Kim HJ, et al: Pachymic Acid Induces Apoptosis of EJ Bladder Cancer Cells by DR5 Up-Regulation, ROS Generation, Modulation of Bcl-2 and IAP Family Members. Phytother Res 29: 1516-1524, 2015.

10. Zamzami N, Susin SA, Marchetti P,Hirsch T, Gómez-Monterrey I, Castedo M and Kroemer G: Mitochondrial control of nuclear apoptosis. J Exp Med 183: 1533-1544, 1996.

11. Hengartner MO: The biochemistry of apoptosis. Nature 407: 770-776, 2000

12. Cregan SP, Dawson VL and Slack RS: Role of AIF in caspase-dependent and caspase-independent cell death. Oncogene 23: 2785-2796, 2004.

13. Findley HW, Gu L, Yeager AM and Zhou M: Expression and regulation of $\mathrm{Bcl}-2, \mathrm{Bcl}-\mathrm{xl}$, and $\mathrm{Bax}$ correlate with p53 status and sensitivity to apoptosis in childhood acute lymphoblastic leukemia. Blood 89: 2986-2993, 1997.

14. DiPaola RS: To arrest or not to G(2)-M Cell-cycle arrest: Commentary re: A. K. Tyagi et al., Silibinin strongly synergizes human prostate carcinoma DU145 cells to doxorubicin-induced growth inhibition, $\mathrm{G}(2)-\mathrm{M}$ arrest, and apoptosis. Clin. cancer res., 8: 3512-3519, 2002. Clin Cancer Res 8: 3311-3314, 2002.

15. Adams JM: Ways of dying: multiple pathways to apoptosis Genes Dev 17: 2481-2495, 2003.

16. Gibbs WW: Untangling the roots of cancer. Sci Am 289: 56-65, 2003.

17. Lee HJ, Nagappan A, Park HS, Hong GE, Yumnam S, Raha S, Saralamma VV,Lee WS, Kim EH and KimGS: Flavonoidsisolated from Citrus platymamma induce mitochondrial-dependent apoptosis in AGS cells by modulation of the PI3K/AKT and MAPK pathways. Oncol Rep 34: 1517-1525, 2015.

18. Liu BL, Zhang X, Zhang W and Zhen HN: New enlightenment of French Paradox: Resveratrol's potential for cancer chemoprevention and anti-cancer therapy. Cancer Biol Ther 6: 1833-1836, 2007.

19. Hatcher H, Planalp R, Cho J, Torti FM and Torti SV: Curcumin: From ancient medicine to current clinical trials. Cell Mol Life Sci 65: 1631-1652, 2008

20. Nogata Y, Sakamoto K, Shiratsuchi H, Ishii T, Yano M and Ohta H: Flavonoid composition of fruit tissues of citrus species. Biosci Biotechnol Biochem 70: 178-192, 2006.

21. Benavente-Garcia O and Castillo J: Update on uses and properties of citrus flavonoids: New findings in anticancer, cardiovascular and anti-inflammatory activity. J Agric Food Chem 56: 6185-6205, 2008.

22. Luo G, Guan X and Zhou L: Apoptotic effect of citrus fruit extract nobiletin on lung cancer cell line A549 in vitro and in vivo. Cancer Biol Ther 7: 966-973, 2008.

23. Lai CS, Li S, Miyauchi Y, Suzawa M, Ho CT and Pan MH: Potent anti-cancer effects of citrus peel flavonoids in human prostate xenograft tumors. Food Funct 4: 944-949, 2013.

24. Park KI, Park HS, Nagappan A, Hong GE, Lee do H, Kang SR, Kim JA, Zhang J, Kim EH, Lee WS, et al: Induction of the cell cycle arrest and apoptosis by flavonoids isolated from Korean Citrus aurantium L. Food Chem 135: 2728-2735, 2012. 
25. Donzelli M and Draetta GF: Regulating mammalian checkpoints through Cdc25 inactivation. EMBO Rep 4: 671-677, 2003.

26. Parrish AB, Freel CD and Kornbluth S: Cellular mechanisms controlling caspase activation and function. Cold Spring Harb Perspect Biol 5: a008672, 2013.

27. Slee EA, Adrain C and Martin SJ: Serial killers: ordering caspase activation events in apoptosis. Cell Death Differ 6: 1067-1074, 1999

28. Wang GH, Mitsui K, Kotliarova S, Yamashita A, Nagao Y, Tokuhiro S, Iwatsubo T, Kanazawa I and Nukina N: Caspase activation during apoptotic cell death induced by expanded polyglutamine in N2a cells. Neuroreport 10: 2435-2438, 1999.

29. Harapu CD, Miron A, Cuciureanu M and Cuciureanu R: Flavonoids-bioactive compounds in fruits juice. Rev Med Chir Soc Med Nat Iasi 114: 1209-1214, 2010 (In Romanian).

30. Lee DH, Park KI, Park HS, Kang SR, Nagappan A, Kim JA Kim EH, Lee WS, Hah YS, Chung HJ, et al: Flavonoids isolated from Korea Citrus aurantium L. Induce G2/M phase arrest and apoptosis in human gastric cancer AGS Cells. Evid Based Complement Alternat Med 2012: 515901, 2012.

31. Kim JA, Park HS, Park KI, Hong GE, Nagappan A, Zhang J, Han DY, Shin SC, Won CG, Kim EH and Kim GS: Proteome analysis of the anti-inflammatory response of flavonoids isolated from Korean Citrus aurantium L. In lipopolysaccharide-induced L6 rat skeletal muscle cells. Am J Chin Med 41: 901-912, 2013.

32. Kim DI, Lee SJ, Lee SB, Park K, Kim WJ and Moon SK Requirement for Ras/Raf/ERK pathway in naringin-induced G1-cell-cycle arrest via p21WAF1 expression. Carcinogenesis 29: $1701-1709,2008$

33. Boonstra J and Post JA: Molecular events associated with reactive oxygen species and cell cycle progression in mammalian cells. Gene 337: 1-13, 2004.

34. Nicolini F, Burmistrova O, Marrero MT, Torres F, Hernández C, Quintana J and Estévez F: Induction of G2/M phase arrest and apoptosis by the flavonoid tamarixetin on human leukemia cells. Mol Carcinog 53: 939-950, 2014.
35. Li Y, Duan S, Jia H, Bai C, Zhang L and Wang Z: Flavonoids from tartary buckwheat induce G2/M cell cycle arrest and apoptosis in human hepatoma HepG2 cells. Acta Biochim Biophys Sin (Shanghai) 46: 460-470, 2014.

36. Tao L, Fu R, Wang X, Yao J, Zhou Y, Dai Q, Li Z, Lu N and Wang W: LL-202, a newly synthesized flavonoid, inhibits tumor growth via inducing $\mathrm{G}(2) / \mathrm{M}$ phase arrest and cell apoptosis in MCF-7 human breast cancer cells in vitro and in vivo. Toxicol Lett 228: 1-12, 2014.

37. Majno G and Joris I: Apoptosis, oncosis and necrosis. An overview of cell death. Am J Pathol 146: 3-15, 1995.

38. Mao WP, Ye JL, Guan ZB, Zhao JM, Zhang C, Zhang NN, Jiang P and Tian T: Cadmium induces apoptosis in human embryonic kidney (HEK) 293 cells by caspase-dependent and-independent pathways acting on mitochondria. Toxicol In Vitro 21: 343-354, 2007.

39. Lazebnik YA, Kaufmann SH, Desnoyers S, Poirier GG and Earnshaw WC: Cleavage of poly (ADP-ribose) polymerase by a proteinase with properties like ICE. Nature 371: 346-347, 1994.

40. Debatin KM: Apoptosis pathways in cancer and cancer therapy. Cancer Immunol Immunother 53: 153-159, 2004.

41. MacKenzie SH and Clark AC: Targeting cell death in tumors by activating caspases. Curr Cancer Drug Targets 8: 98-109, 2008.

42. Wong WW and Puthalakath $\mathrm{H}$ : Bcl-2 family proteins: The sentinels of the mitochondrial apoptosis pathway. IUBMB Life 60: 390-397, 2008.

43. Cai J, Yang J and Jones DP: Mitochondrial control of apoptosis: the role of cytochrome c. Biochim Biophys Acta 1366: 139-149, 1998.

44. Liu X, Kim CN, Yang J, Jemmerson R and Wang X: Induction of apoptotic program in cell-free extracts: requirement for dATP and cytochrome c. Cell 86: 147-157, 1996.

45. Shin DY, Ryu CH, Lee WS, Kim DC, Kim SH, Hah YS, Lee SJ, Shin SC, Kang HS and Choi YH: Induction of apoptosis and inhibition of invasion in human hepatoma cells by anthocyanins from meoru. Ann N Y Acad Sci 1171: 137-148, 2009. 